\title{
GLOBAL EFFECTIVENESS OF PULSATING HEAT PIPE HEAT EXCHANGERS: MODELING AND EXPERIMENTS
}

\section{Sameer Khandekar, ${ }^{1, *}$ Vivek Silwal, ${ }^{1}$ Ashutosh Bhatnagar, ${ }^{1} \mathcal{E}$ Pavan Sharma ${ }^{2}$}

\author{
${ }^{1}$ Department of Mechanical Engineering, Indian Institute of Technology Kanpur, \\ Kanpur (UP) 208016 India \\ ${ }^{2}$ Reactor Safety Division, Bhabha Atomic Research Center, Trombay, Mumbai, \\ 400076 India
}

*Address all correspondence to Sameer Khandekar E-mail: samkhan@iitk.ac.in

Original Manuscript Submitted: 6/20/2011; Final Draft Received: 7/20/2011

\begin{abstract}
Pulsating heat pipes (PHPS) are an interesting class of passive two-phase heat transfer systems incorporating self-excited thermally driven oscillations for achieving a high rate of heat transfer. While many applications of PHPs have emerged, a systematic analysis of heat exchangers based on this technology has not been reported. In this work, two possible configurations of PHP-based heat exchangers, for process waste heat exchange as well as high heat flux handling needs, respectively, have been explored, scrutinized, and analyzed. These two configurations are (1) temperature-controlled liquid-liquid non-contact-type heat exchangers and (2) heat flux-controlled air-cooled systems. These two types of systems are performance tested under different operating conditions. Given the fact that the fundamental transport modeling scheme for PHPs is still not available, it is shown that global modeling of these devices can still be achieved. The temperature controlled PHP system is effectively modeled by conventional heat exchanger analysis techniques; i.e., the NTU-E method. The heat fluxcontrolled PHP system is modeled by fin analogy employing the conventional theory of extended surface heat transfer, as applicable to diffusion fins. The mathematical modeling with these two systems is presented and limitations of global modeling are also discussed. The effectiveness values for the temperature-controlled heat exchanger system consisting of bare and un-finned PHP tubes, operating under gravity-assisted mode, were of the order of $\sim 0.25-0.45$. The heat flux controlled mode has more favorable performance with overall thermal resistance lower than $\sim 0.2 \mathrm{~K} / \mathrm{W}$, corresponding to an effective thermal conductivity of PHPS in the range of 500-4500 W/mK for simple air cooling on bare tubes.
\end{abstract}

KEY WORDS: pulsating heat pipe, passive two-phase heat exchangers, effectiveness, fins

\section{INTRODUCTION}

Innovative heat exchangers are needed to harness or transport energy from various process industry operations. The available thermal energy may often be low-grade and distributed. In addition, high heat flux removal, at safe maximum operating temperatures, is needed for power electronics thermal management and transport requirements. The 


\section{NOMENCLATURE}

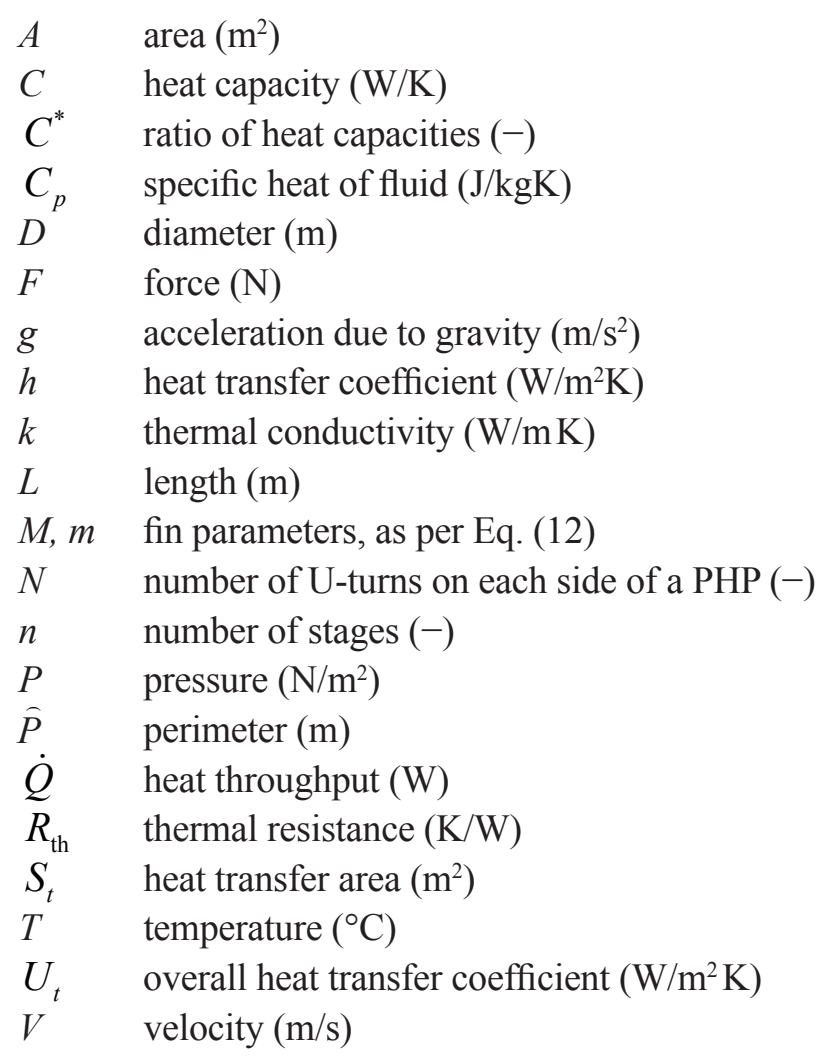

\section{Non-Dimensional Numbers}

Bi Biot number, $(h \cdot D) / k_{\text {solid }}$

Bo Bond number, $D \cdot\left(g\left(\rho_{\text {liq }}-\rho_{\text {vap }}\right) / \sigma\right)^{0.5}$

NTU number of transfer units, $(U \cdot S) / C$

$\mathrm{Nu} \quad$ Nusselt number, $(h \cdot D) / k_{\text {liq }}$

Pr Prandtl number, $\left(\mu_{\text {liq }} \cdot C_{p}\right) / k_{\text {liq }}$

Re Reynolds number, $\left(\rho_{l i q} \cdot V \cdot D\right) / \mu_{l i q}$

\section{Greek Symbols}
$\varepsilon \quad$ effectiveness (-)
$\mu \quad$ dynamic viscosity (Pa.s)
$\rho \quad$ density $\left(\mathrm{kg} / \mathrm{m}^{3}\right)$
$\sigma \quad$ surface tension of the fluid $(\mathrm{N} / \mathrm{m})$

\section{Subscripts}

$\begin{array}{ll}\text { av } & \text { average } \\ c & \text { cold fluid }\end{array}$




$\begin{array}{ll}\text { ci, co } & \text { cold inlet, cold outlet } \\ \text { cs } & \text { cross-section } \\ \text { eff } & \text { effective } \\ h & \text { hot fluid } \\ \text { hi, ho } & \text { hot inlet, hot outlet } \\ i & \text { inner } \\ \text { liq } & \text { liquid phase } \\ \text { max } & \text { maximum } \\ \text { min } & \text { minimum } \\ o & \text { outer } \\ s & \text { surface } \\ \text { sat } & \text { saturation } \\ \text { vap } & \text { vapor phase }\end{array}$

range of pulsating heat pipe (PHP) two-phase systems, introduced in the latter part of the last century, have many attractive aspects (Akachi, 1990; Akachi et al., 1996). Passive operation, high heat flux handling, ease of manufacture, and interesting thermo-fluidic two-phase transport from an academic viewpoint, are some of the striking features of this class of heat pipes (Khandekar, 2004).

Conventional wicked heat pipe heat exchangers have been routinely used for gasgas heat exchangers for waste heat recovery and air preheating/economizer applications (Vasiliev, 2005). A PHP heat exchanger has several advantages over conventional heat pipe systems with potentially many applications (Vasiliev, 2005). Two principal operating modes that are possible for a PHP heat exchanger are (1) heat flux-controlled operation and (2) temperature-controlled operation. Under the heat flux-controlled mode such structures are inherently capable of handling high heat fluxes ranging from $1 \mathrm{~W} / \mathrm{cm}^{2}$ to over $60 \mathrm{~W} / \mathrm{cm}^{2}$. Under the temperature-controlled mode, not many experimental studies are available (Khandekar, 2010).

In this work we explore the global behavior of the following two types of PHP heat exchangers: (1) a temperature-controlled (liquid-liquid) module and (b) a heat flux-controlled air-cooled module. As we will see, in spite of the fact that a fundamental level of transport modeling of PHPs has not been achieved to date (Zhang and Faghri, 2008; Das et al., 2010; Khandekar et al., 2010), the statistical global behavior of such PHP-based heat exchangers can still be predicted by the approaches proposed in this paper.

\section{TEMPERATURE-CONTROLLED SYSTEM}

In this section we first describe a PHP heat exchanger that is temperature-controlled and designed to transfer heat from one liquid to the other, without any mutual mixing of the heat transfer liquids. The global performance modeling methodology of such PHP structures with NTU-effectiveness (NTU- $\varepsilon$ ) is then outlined. 


\subsection{Experimental Setup (Module \#1)}

Module \#1 was designed for passive heat transfer between two liquids without mutual mixing, the details of which are shown in Fig.1. The PHP matrix was made of a simple copper tube with an inside diameter (ID) of $1.8 \mathrm{~mm}$ and outside diameter (OD) of 2.0 $\mathrm{mm}$. A stainless steel splitter plate of size $256 \mathrm{~mm} \times 146 \mathrm{~mm} \times 8 \mathrm{~mm}$ was size was placed in between the PHP matrix. This plate had 120 holes (longitudinal pitch $=$ transverse pitch $=12 \mathrm{~mm}$ ) arranged in staggered mode, as shown in Fig. 1(a), to accommodate the PHP matrix. U-shaped copper capillary tubes were brazed on both sides of these holes forming a complete and endless closed-loop PHP. The height of every loop was $150 \pm 1 \mathrm{~mm}$ on both sides of the splitter plate. There were no additional fins or extended surfaces of the PHP tubes; they were bare copper capillary tubes. The net internal volume of the PHP was measured to be $92 \pm 2 \mathrm{~mL}$. The working fluid inside the PHP was pure degassed ethanol in all tests.

This PHP matrix was assembled inside a stainless steel casing with two separate chambers in which the flow arrangement of hot and cold fluid flow was done, as shown in Fig. 1(b). The complete schematic of the experimental arrangement is shown in Fig. 1(c). Two separate temperature-controlled baths were used to circulate hot and cold water, between which heat transfer was desired. All experiments have been done with
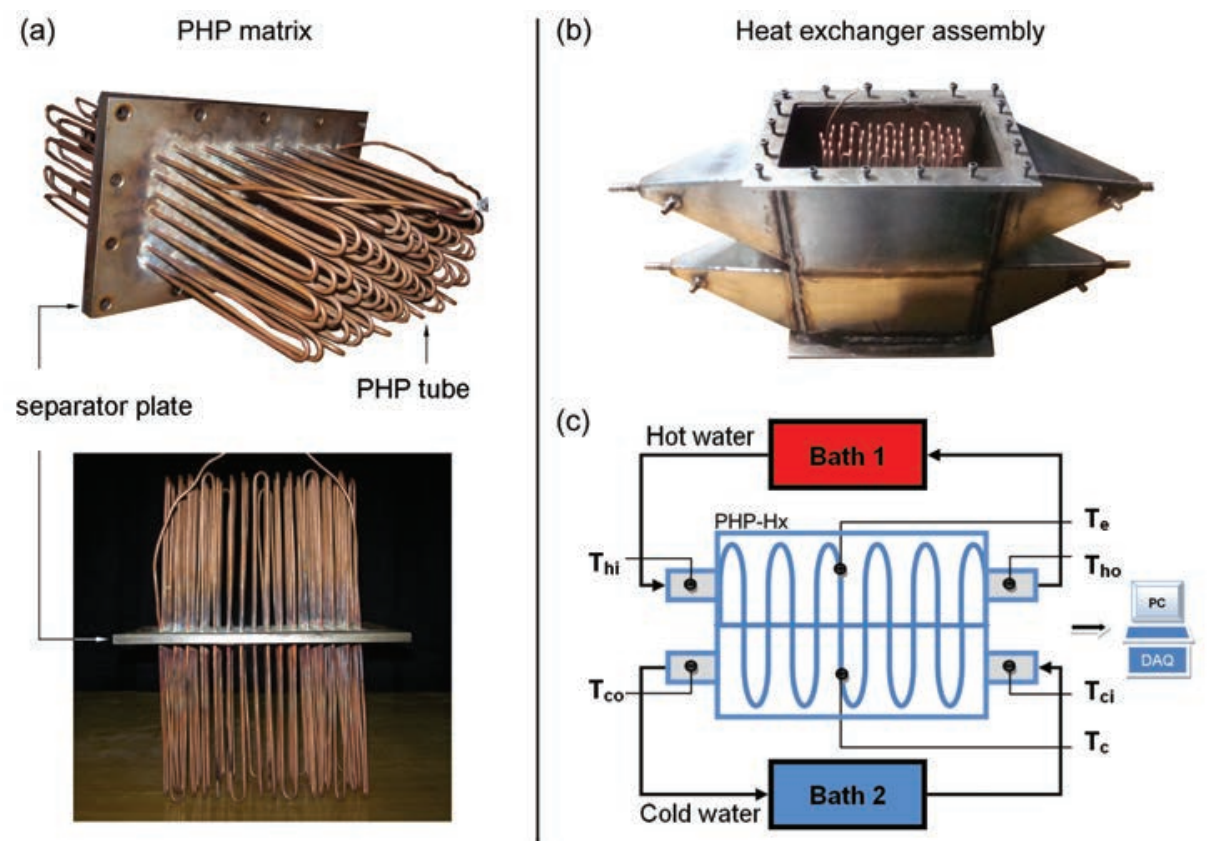

FIG 1: Details of the experimental setup showing (a) the construction of PHP Module \#1, (b) the heat exchanger assembly with the outer casing and coolant flow chambers, and (c) a schematic of the complete setup with instrumentation 
three different hot water inlet temperatures $\left(60^{\circ} \mathrm{C}, 75^{\circ} \mathrm{C}\right.$ and $80^{\circ} \mathrm{C}$; all at fixed flow rate of $1.18 \times 10^{-4} \mathrm{~m}^{3} / \mathrm{s}$ ) while the cold water inlet temperature was always kept constant at $35^{\circ} \mathrm{C}$ (flow rate $=1.6 \times 10^{-5} \mathrm{~m}^{3} / \mathrm{s}$ ). Type-K thermocouples with $1.0 \mathrm{~mm}$ bead diameter and accuracy of $\pm 0.2^{\circ} \mathrm{C}$ after calibration were inserted at suitable locations in the inlet and outlet plenums to get the respective temperatures of the heat exchanging fluids. Two thermocouples were also placed on the central U-tubes of the PHP $\left(T_{e}\right.$ and $\left.T_{c}\right)$, on both sides of the separator plate, as shown in Fig. 1(c). Maximum ambient heat losses were limited to $7-11 \%$.

\subsection{NTU-Effectiveness Formulation (Module \#1)}

In a conventional heat pipe/thermosyphon heat exchanger, heat is transferred between the high- and low-temperature fluids by evaporation and condensation of the heat pipe working fluid. In such a configuration, the maximum heat capacity is due to the phase change of the heat pipe working fluid. This fact leads to the analysis of the heat pipe heat exchangers as two separate heat exchangers, coupled by the heat pipe working fluid, which is similar to a liquid-coupled indirect-transfer heat exchanger, as shown schematically in Fig. 2(a). The equivalent heat exchanger system represented by Fig. 2(b) and the subsequent analysis are valid as long as the external heat transfer capacity of the heat exchanger system is an order of magnitude smaller than the internal heat capacity of the heat pipe (due to evaporation and condensation). In a conventional heat pipe, all of the heat transfer is by latent heat transfer of the working fluid; the PHP heat transport mechanism is a combination of latent and sensible heat, as noted earlier. While the exact percentage of latent heat and sensible heat transfer in a PHP is debatable and still under scrutiny, it can still be safely said that internal heat transfer resistance is quite low. With this background, we explore the possibility of applying the effectiveness formulation for conventional heat pipe exchangers, as given by (Kays and London, 1984), to PHP-based heat exchangers, as shown in Fig. 2(c).

(a)

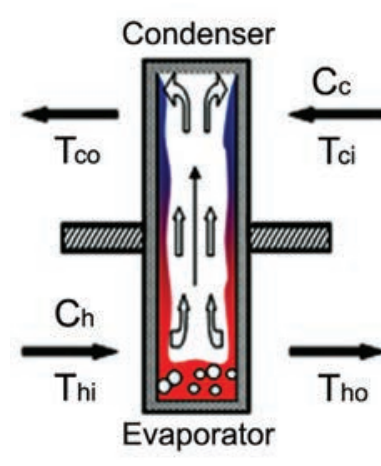

Conventional heat pipe (b)

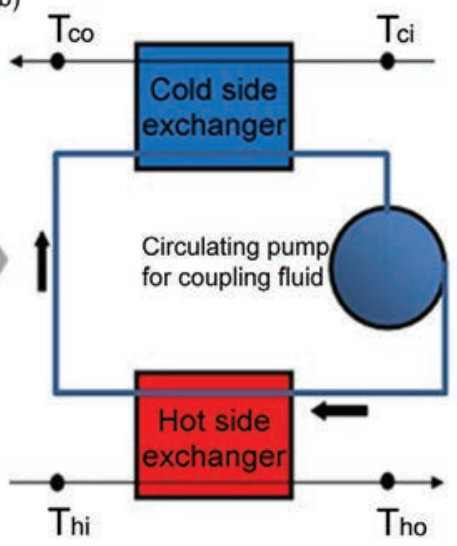

(c)

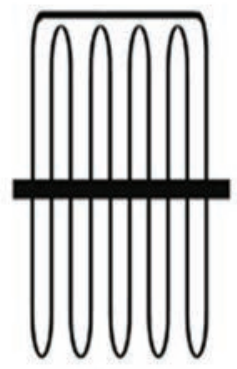

PHP

FIG 2: (a) Conventional heat pipe heat exchanger, (b) equivalent liquid-coupled indirect-transfer heat exchanger model for the heat pipe heat exchanger, and (c) PHP-based heat exchanger 
The effectiveness of any heat exchanger is defined as

$$
\varepsilon=\frac{\dot{Q}_{\mathrm{actual}}}{\dot{Q}_{\max }}=\frac{C_{h}\left(T_{\mathrm{hi}}-T_{\mathrm{ho}}\right)}{C_{\min }\left(T_{\mathrm{hi}}-T_{\mathrm{ci}}\right)}=\frac{C_{c}\left(T_{\mathrm{co}}-T_{\mathrm{ci}}\right)}{C_{\min }\left(T_{\mathrm{hi}}-T_{\mathrm{ci}}\right)}
$$

The effectiveness of a typical counter-flow heat exchanger is given as (Incropera et al., 2007)

$$
\varepsilon=\frac{1-\exp \left[-\frac{U_{t} S_{t}}{C_{\min }}\left(1-\frac{C_{\min }}{C_{\max }}\right)\right]}{1-\frac{C_{\min }}{C_{\max }} \exp \left[-\frac{U_{t} S_{t}}{C_{\min }}\left(1-\frac{C_{\min }}{C_{\max }}\right)\right]}
$$

where $U_{t}$ and $S_{t}$ are the overall heat transfer coefficient and heat transfer area on one side of the heat exchanger, respectively. As the maximum heat capacity (in a heat pipe as well as in a PHP) is several orders of magnitude larger than the minimum, due to phase change, (this is the principal basis of the present analysis), and Eq. (2) is reduced to

$$
\varepsilon=1-\exp (-\mathrm{NTU})
$$

With reference to Fig. 2(b), which shows the equivalent heat exchanger system representing the single heat pipe heat exchanger, the respective effectiveness values of the evaporator and condenser sections can thus be defined as

$$
\varepsilon_{i}=1-\exp \left(-\mathrm{NTU}_{i}\right)
$$

where

$$
\mathrm{NTU}_{i}=\frac{U_{i} S_{i}}{C_{i}}: i=h, c
$$

The external heat transfer coefficient over the PHP tubes was modeled as singlephase external flow over a bank of staggered tubes. For staggered tube banks with 16 or more rows and $0<\operatorname{Re}_{D}<500$ and $0.7<\operatorname{Pr}<500$, the average Nusselt number is given by (Incropera et al., 2007)

$$
\mathrm{Nu}_{D_{o}}=1.04 \operatorname{Re}_{D_{o}}^{0.4} \times \operatorname{Pr}^{0.36} \times\left(\operatorname{Pr} / \operatorname{Pr}_{\mathrm{s}}\right)^{0.25}
$$

In this correlation, all properties except $\operatorname{Pr}_{s}$ are to be evaluated at the arithmetic mean of the inlet and the outlet temperatures of the fluid and $\operatorname{Pr}_{s}$ are to be evaluated at the surface temperature of the tube [see Fig. 1(c), $T_{e}$ and $T_{c}$ ). Here, $D_{o}$ is taken as the OD of the PHP tube and $\mathrm{Re}_{D_{o}}$ is the local Reynolds number experienced by the staggered tube bank. 
For an individual heat pipe, the effectiveness is defined as (Kays and London, 1984)

$$
\varepsilon_{\text {pipe }}=\left(\frac{1}{\varepsilon_{\min }}+\frac{C^{*}}{\varepsilon_{\max }}\right)^{-1}
$$

where $\varepsilon_{\min }$ and $\varepsilon_{\max }$ are the minimum and maximum values of $\varepsilon_{h}$ and $\varepsilon_{c}$, respectively, from Eq. (4). The heat capacity ratio $C^{*}$ is given by

$$
C^{*}=\frac{C_{\min }}{C_{\max }} \quad \text { such that } C^{*} \leq 1.0
$$

where $C_{\max }$ is the larger of the heat capacities of the high- and low-temperature fluid streams and $C_{\min }$ is the smaller value, respectively.

For a single stage of heat pipes in the heat exchanger, $S_{h}$ and $S_{c}$ are based on the total heat transfer area in that stage. For a multi-stage heat pipe heat exchanger, in which there are a number of stages, each containing a column of heat pipes (normal to the highand low-temperature fluid streams), the effectiveness can be determined by considering the columns of heat pipes as separate heat exchangers connected together in series, similar to that of a multi-pass heat exchanger. For such a multi-stage system in counter-flow arrangement, the heat exchanger effectiveness is given by (Kays and London, 1984)

$$
\varepsilon=\frac{\left(\frac{1-C^{*} \varepsilon_{p}}{1-\varepsilon_{p}}\right)^{n}-1}{\left(\frac{1-C^{*} \varepsilon_{p}}{1-\varepsilon_{p}}\right)^{n}-C^{*}}
$$

where $\mathrm{n}$ is the number of stages and $C^{*}$ is defined by Eq. (8).

\section{HEAT FLUX-CONTROLLED SYSTEM}

In such a configuration, rather than controlling the temperature difference between the evaporator and the condenser, we control the heat flux at the evaporator and use standard air cooling at ambient temperature. As the self-sustained pumping action of the PHP depends on the rate of growth of bubbles in the evaporator and the rate at which energy is imparted to them, the heat flux is an important influence parameter for controlling the performance (Khandekar, 2004). Therefore, we report here two heat flux-controlled modules, which are rather similar in construction and operation (the major difference being the number of turns).

\subsection{Experimental Setup (Module \#2)}

The details of the setup are shown in Fig. 3. The PHP module was formed by brazing a continuous copper capillary tube array of $\mathrm{ID}=2.0 \mathrm{~mm}$ and $\mathrm{OD}=3.0 \mathrm{~mm}$, shaped in ser- 


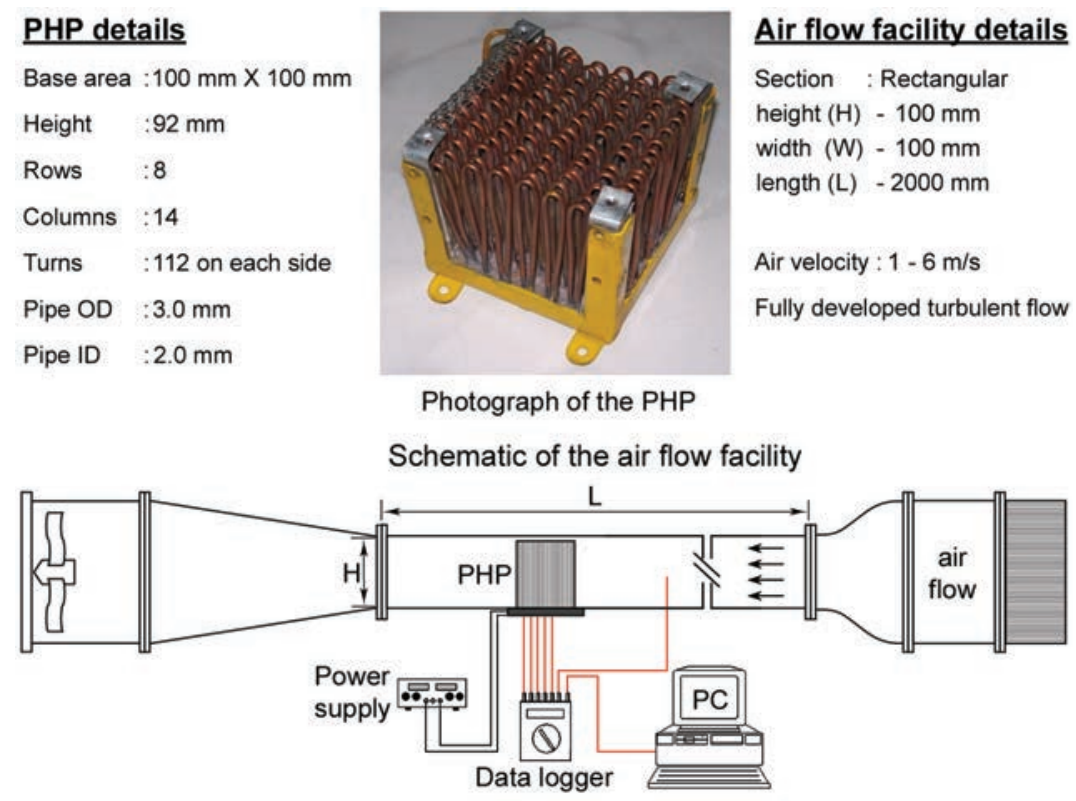

FIG 3: Details of the (a) air-cooled PHP Module \#2 and (b) air-flow facility

pentine U-shaped loops, on a copper base plate of $100 \mathrm{~mm} \times 100 \mathrm{~mm} \times 4 \mathrm{~mm}$ size. The net volume of the PHP was $65 \pm 2 \mathrm{~mL}$; the working fluid was ethanol in all experiments. In this array, there were eight rows and every row had 14 pipe loops. The height of every loop was $92 \pm 1 \mathrm{~mm}$. The PHP array was attached to a surface mountable flat heater and kept inside an air-flow control facility wherein the cooling air velocity was controlled. The average PHP heater block and base plate temperature were measured by four Kthermocouples with $1.5 \mathrm{~mm}$ bead diameter; one thermocouple measured the inlet air temperature and two thermocouples measured the outlet temperature of the cooling air. All thermocouples were calibrated against a Pt-100 RTD with an accuracy of $\pm 0.2^{\circ} \mathrm{C}$, after calibration. The centerline air velocity in the flow facility was varied from $1 \mathrm{~m} / \mathrm{s}$ to $6 \mathrm{~m} / \mathrm{s}$ with ambient temperatures of $25^{\circ} \mathrm{C} \pm 1.5^{\circ} \mathrm{C}$. The air velocity was recorded with a pre-calibrated hot wire sensor with a linear output signal of $0-10 \mathrm{~V}$ (thermo-anemometer, range $0.1-20 \mathrm{~m} / \mathrm{s}$, maximum error less than $\pm 0.3 \mathrm{~m} / \mathrm{s}$ for air conditions $10^{\circ} \mathrm{C}-36^{\circ} \mathrm{C}$, RH 45\%, $\left.1.013 \times 10^{5} \mathrm{~Pa}\right)$.

\subsection{Experimental Setup (Module \#3)}

The details of this module are shown in Fig. 4(a). The setup consisted of a copper block of $130 \times 25 \times 25 \mathrm{~mm}^{3}$ size with four cartridge heaters forming the evaporator. The PHP was fabricated from a copper tube with $2.0 \mathrm{~mm}$ ID and $3.0 \mathrm{~mm}$ OD, with 20 turns on each side (a total of 40 U-turns), having a staggered pitch of $10 \mathrm{~mm}$ between the tubes. The total length of the tube used was about $5.4 \mathrm{~m}$ with a net volume of $17.0 \mathrm{~mL}$. To 
(a)

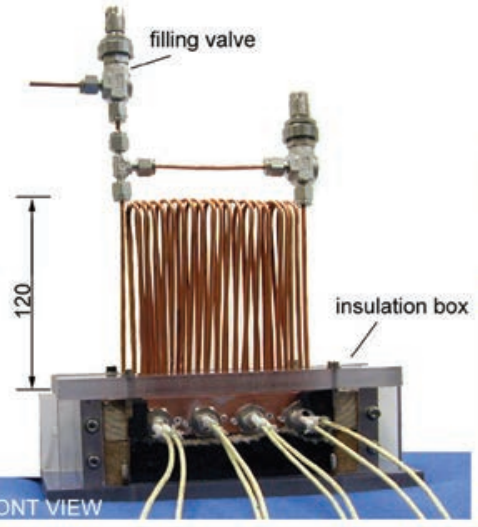

(b)

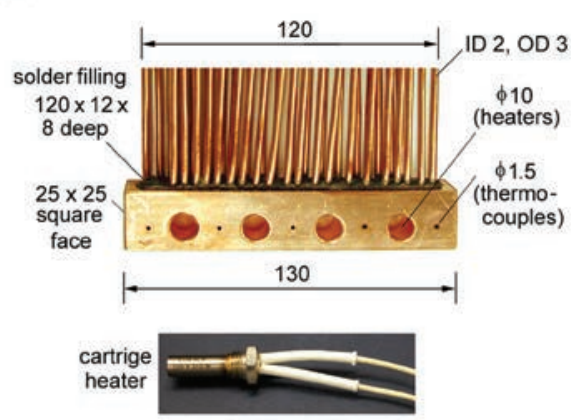

Evaporator details Photographs of Module \#3

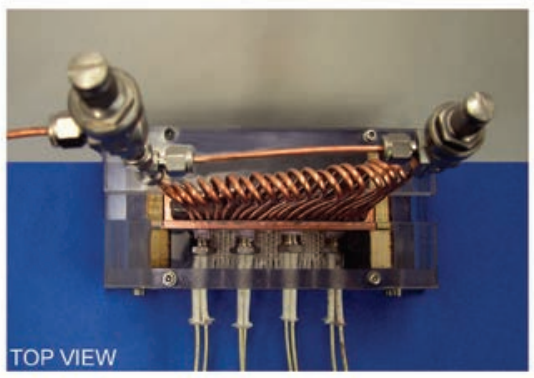

(c)

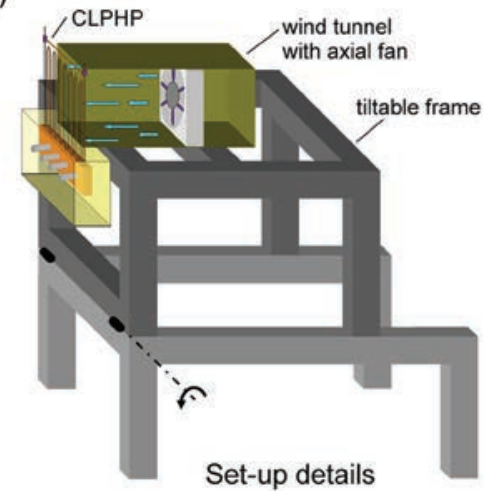

FIG 4: Details of PHP heat exchanger Module \#3: (a) front view and tope view photograph, (b) details of the evaporator, and (c) module mounted on the frame with the fan

accommodate the U-turns of the PHP, a preformed cavity (size $120 \mathrm{~mm} \times 12 \mathrm{~mm} \times 8$ mm size) was machined into the copper block; the PHP U-turns were soldered into this cavity, as shown in Fig. 4(b). Leaving apart the soldered length of the U-turns embedded into the evaporator block, the entire PHP was cooled by forced air cooling. A length of about $100 \mathrm{~mm}$ was exposed to the coolant air, as shown in Fig. 4(b). In this module the average air velocity was always maintained constant at $3.5 \mathrm{~m} / \mathrm{s}$ with ambient air temperature of $25^{\circ} \mathrm{C} \pm 1.5^{\circ} \mathrm{C}$. The entire setup was mounted on a revolving frame so that the experiments could be performed at all orientations, as shown in Fig. 4(c). The working fluid, in all experiments was again ethanol.

\subsection{Extended Surface Fin Formulation}

One way of looking at these two PHP modules is from an extended surfaces point of view. For example, the PHP tubes can be seen as fins protruding out of the evaporator block, as shown in Fig. 5. 


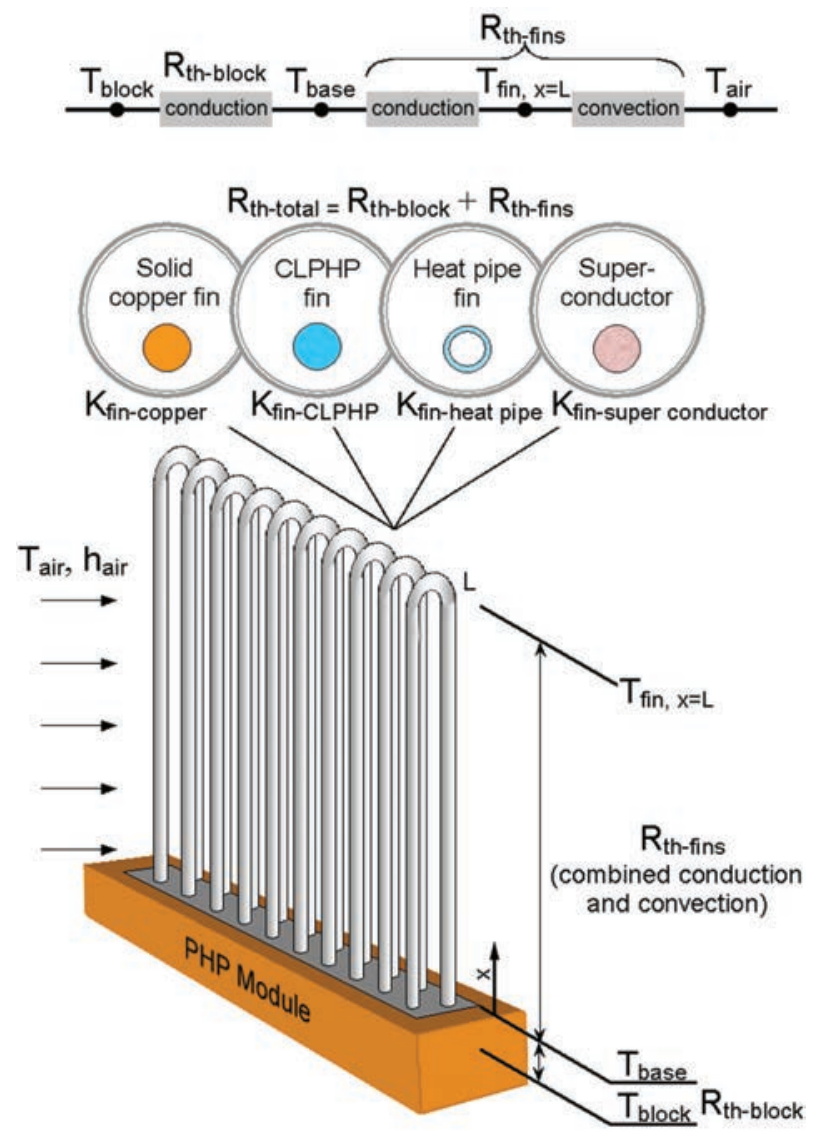

FIG 5: The extended surface fin analogy for modeling the heat transfer through a heat fluxcontrolled pulsating heat pipe heat exchanger

The Biot number of the finned systems affects the longitudinal temperature distribution along the fin, which directly influences the resulting enhancement of heat transfer due to the fins. In the limit of infinite fin thermal conductivity $(\mathrm{Bi} \rightarrow 0)$, the entire fin would be at the base temperature, thereby providing a maximum possible heat transfer rate. An ideal conventional heat pipe represents this case. In practice though, heat pipes also have a finite thermal resistance. With this viewpoint, and referring to Fig. 5, three pertinent questions emerge:

- What is the comparison between PHPs, in terms of thermal resistance and weight, and an equivalent solid copper-based fin system?

- What is the comparison between PHPs, in terms of thermal resistance and weight, and an equivalent conventional heat pipe fin system?

- What are the limitations of studying a PHP-based system from an extended surface fin point of view? 
A typical weight ratio comparison of PHP tubes with a solid copper rod is $\sim 0.45$. Performance testing of conventional copper-water mini-heat pipes indicates that the maximum performance drastically reduces while the thermal resistance increases, with decreasing heat pipe diameter (Tang et al., 2004). In addition, the manufacturing complexity of small diameter conventional capillary heat pipes also increases with decreasing tube diameter. The estimated $k_{\text {eff }}$ (based on heat pipe OD) in vertical heater-down position, optimized for the range of operating temperatures tested $\left(30-80^{\circ} \mathrm{C}\right)$, is shown in Table 1 (Tang et al., 2004). This provides an order of magnitude indication to the designer of what is practically achievable by copper-water conventional cylindrical miniheat pipes. With an improved fabrication process it may be possible to somewhat enhance these figures but based on the fact that the tested mini-heat pipes were supplied by competent and established manufacturers, the possible enhancement range is believed not to be significant.

TABLE 1: Effective thermal conductivity of mini-heat pipes in vertical heater-down position (Tang et al., 2004)

\begin{tabular}{|c|c|c|c|c|c|}
\hline $\begin{array}{c}\mathbf{I D} / \mathbf{O D} \\
(\mathrm{mm})\end{array}$ & $\begin{array}{c}\dot{Q}_{\max } \text { at } \\
\boldsymbol{T}_{a}=\mathbf{6 0}^{\circ} \mathbf{C}\end{array}$ & $\begin{array}{c}\boldsymbol{R}_{\text {th }} \\
(\mathrm{K} / \mathrm{W})\end{array}$ & $\begin{array}{c}\boldsymbol{L}_{\text {eff }} \\
(\mathrm{mm})\end{array}$ & $\begin{array}{c}\boldsymbol{A}_{\mathrm{cs}} \\
\left(\mathrm{mm}^{2}\right)\end{array}$ & $\begin{array}{c}\boldsymbol{k}_{\text {eff }} \\
(\mathrm{W} / \mathrm{mK})\end{array}$ \\
\hline $3.0 / 4.0$ & 27.0 & 0.3 & 210 & 12.56 & 55732 \\
\hline $2.5 / 3.0$ & 21.5 & 1.1 & 96 & 7.07 & 12344 \\
\hline $2.0 / 2.5$ & 16.0 & 3.25 & 85 & 4.91 & 5326 \\
\hline
\end{tabular}

To find out the effective thermal conductivity $\left(k_{\text {eff }}\right)$ of tested PHP Modules \#2 and $\# 3$, the air side heat transfer coefficient (i.e., $h_{\text {aip }}$ ) is needed. This is estimated from the dry PHP test (with no fluid inside; FR $=0 \%$, where FR is the filling ratio). By knowing the PHP tube geometry and experimentally obtaining $T_{\text {block }}, T_{\text {base }}, T_{\text {air }}$ and $\dot{Q}_{\text {fin }}$, we can analyze this case by the standard one-dimensional conduction equation in extended surfaces, with convective boundary at the fin tip (Incropera et al., 2007), as

$$
\begin{gathered}
\dot{Q}_{\text {fin }}=M \cdot\left(\frac{\sinh (m L)+\left(h_{\text {air }} / m k_{\text {fin }}\right) \cosh (m L)}{\cosh (m L)+\left(h_{\text {air }} / m k_{\text {fin }}\right) \sinh (m L)}\right)\left(T_{\text {base }}-T_{\text {air }}\right) \\
\dot{Q}_{\text {total }}=(2 N) \cdot \dot{Q}_{\text {fin }}
\end{gathered}
$$

where

$$
\begin{gathered}
M=\sqrt{h_{\mathrm{air}} \cdot \widehat{P} \cdot k_{\mathrm{fin}} \cdot A_{\mathrm{cs}}} ; m=\sqrt{\left(h_{\mathrm{air}} \cdot \widehat{P}\right) /\left(k_{\mathrm{fin}} \cdot A_{\mathrm{cs}}\right)} \\
A_{\mathrm{cs}}=(\pi / 4)\left(D_{o}^{2}-D_{i}^{2}\right) \text { and } \hat{P}=\pi D_{o}
\end{gathered}
$$


For a given cooling air velocity, the air side heat transfer coefficient $\left(h_{\text {air }}\right)$ is applicable in the entire range of PHP experiments (i.e., including those where the PHP is filled and is operating with a two-phase mixture inside the tube). With this known $h_{\text {air }}$, Eq. (10) can again be used to determine the $\left(k_{f i n}\right)_{\text {eff }}$ for all of the cases of interest when the PHP is working.

\section{RESULTS AND DISCUSSION}

\subsection{Temperature-Controlled System (Module \#1)}

Figure 6(b) shows the typical temperature-time history for the PHP with FR $=40 \%$ and operating with the gravity-assisted bottom heating mode. Initially, up to point A both $T_{\mathrm{hi}}$ and $T_{\text {ci }}$ were kept at $35^{\circ} \mathrm{C}$. At point $\mathrm{A}, T_{\mathrm{hi}}$ was set at $60^{\circ} \mathrm{C}$ by the constant temperature bath. After sometime, when steady state was achieved at this temperature, $T_{\mathrm{hi}}$ was again set at $75^{\circ} \mathrm{C}$ at point $\mathrm{B}$, followed by $85^{\circ} \mathrm{C}$ at point $\mathrm{C}$. In this case, the pulsating heat pipe starts operating even at the lowest hot water temperature of $60^{\circ} \mathrm{C}$, as is indicated by the oscillations observed in $T_{e}$ and $T_{c}$. As $T_{\text {hi }}$ increases, the PHP operation becomes more favorable and efficient. For comparison, Fig. 6(a) shows the temperature-time response of the PHP with FR = 0\% (no working fluid inside the system). Obviously, in this case, the heat transfer is only due to the conduction through bare PHP tubes and, thus, the efficiency is insignificant; there is hardly any heat transfer. In anti-gravity mode, as shown in Fig. 6(c), the system does operate at large $T_{\mathrm{hi}}\left(=85^{\circ} \mathrm{C}\right)$, albeit with large oscillations in the temperature profiles in the evaporator and the condenser regions. The heat exchanger efficiency is moderate, lower than in the gravity-assisted mode, as will be discussed next.

Figures 7(a) and (b) show the comparison of net heat throughput for FR $=0 \%$ (dry system), $40 \%, 60 \%$ and $80 \%$, respectively, in the gravity-assisted and anti-gravity modes. Net heat throughput is maximum for $\mathrm{FR}=0 \%$, as compared to other filling ratios in both of the modes. In the anti-gravity mode, the heat pipe heat exchanger starts working effectively only at $T_{h i}\left(=85^{\circ} \mathrm{C}\right)$, as noted earlier. In any case, anti-gravity operation is always somewhat inferior to the gravity-assisted mode. At lower heating temperatures, oscillations in the working fluid temperature [see Figs. 1(c) and $6, T_{e}$ and $T_{c}$ ] are not pronounced; this indicates fewer internal fluid oscillations; thus, explaining the lower overall heat throughput. The best performance was of the order of $1.4 \mathrm{~kW}$ at a temperature difference of $50^{\circ} \mathrm{C}\left(T_{e}=85^{\circ} \mathrm{C}\right.$ and $\left.T_{c}=35^{\circ} \mathrm{C}\right)$, in gravity-assisted mode at $\mathrm{FR}=40 \%$.

Figure 8 shows the comparison of heat exchanger effectiveness, as obtained by using Eqs. (1)-(9), in the gravity-assisted orientation of the heat exchanger at different filling ratios. As can be seen, the effectiveness of the device increases with increasing hot water inlet temperature (the temperature difference between the hot and the cold fluids). A maximum effectiveness of about 0.43 is achieved at the filling ratio of $40 \%$. It is to be noted that no additional finning or surface area enhancement has been done on the exterior of the PHP tubes; i.e., the tubes are bare, as seen in Fig. 1(a). With additional cross-finning, say with metallic foils, to increase the outside heat transfer area, effectiveness can certainly be further enhanced. Effectiveness diminishes with increasing filling 

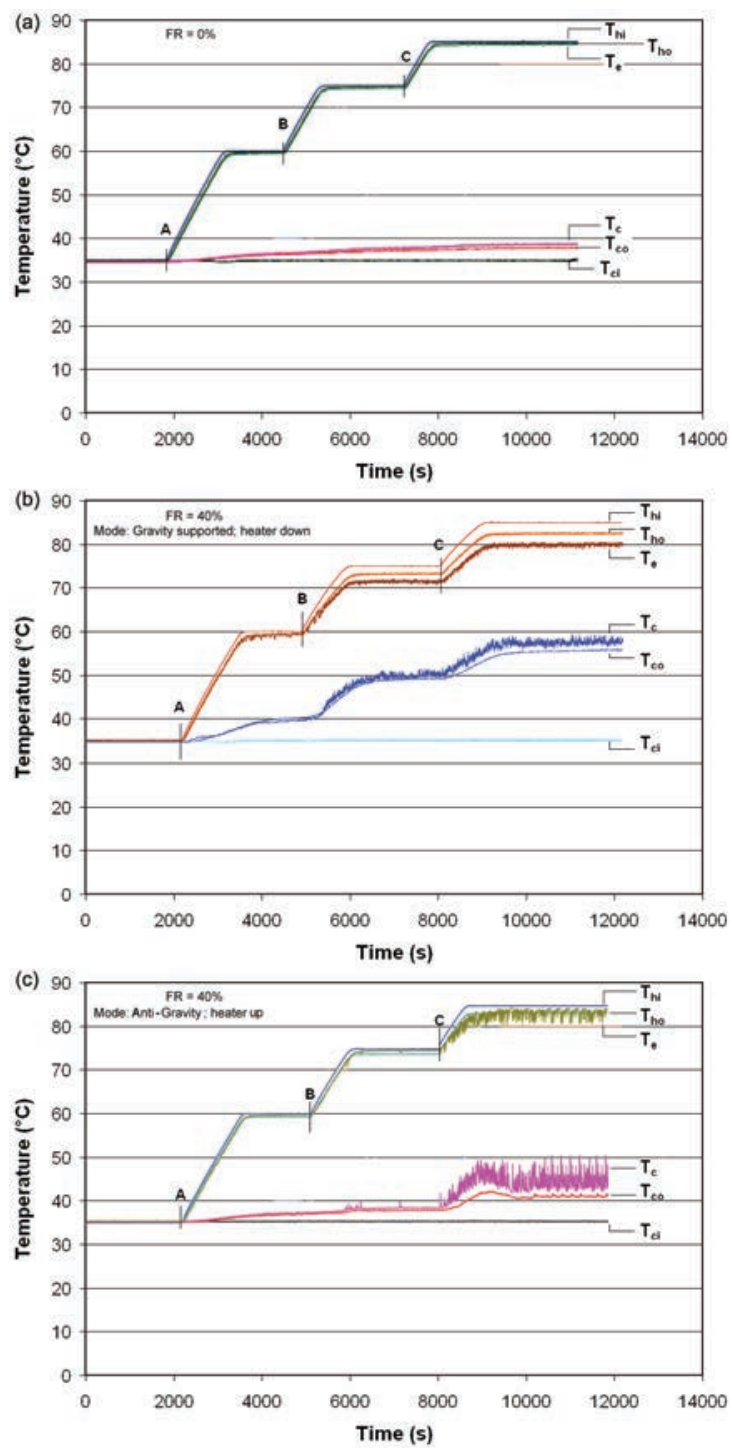

FIG 6: Typical temperature-time history of the temperature-controlled PHP-Hx (Module \#1) at (a) $\mathrm{FR}=0 \%$, (b) $\mathrm{FR}=40 \%$ (gravity-supported operation), and (c) $\mathrm{FR}=40 \%$ (anti-gravity operation)

ratio as the oscillating tendency of the fluid gets hampered. Also, effectiveness values for the anti-gravity mode are, for all cases, lesser than those reported for the gravityassisted mode. These preliminary results also clearly indicate that the NTU- $\varepsilon$ model for a conventional heat pipe is reasonably valid for the PHP, as the thermal capacity of the latter is still quite high-although not as high as in conventional heat pipe systems. More systematic studies are needed to establish these working correlations for the design purpose. 

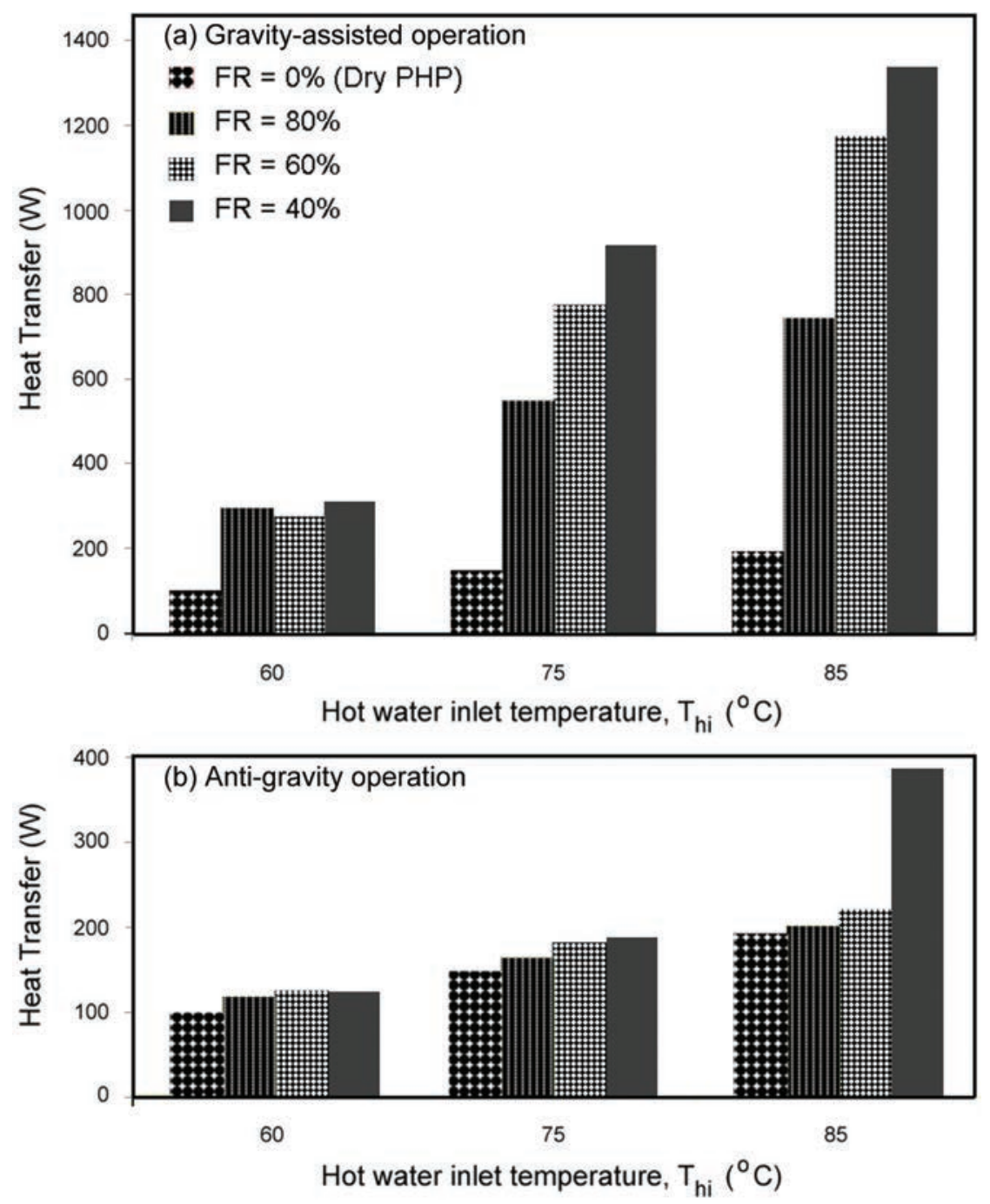

FIG 7: Comparison of the heat throughput of the temperature-controlled PHP-Hx (Module \#1) in (a) gravity-supported orientation and (b) anti-gravity orientation

\subsection{Heat Flux-Controlled System (Module \#2)}

The average evaporator ( $T_{\text {block }}$ ) and condenser (PHP tube tip) temperature (see Fig. 5, $T_{\text {fin }, x=L}$ ) during a typical power ramp-up test is shown in Fig. 9 at FR $=60 \%$ with a centerline coolant air velocity of $6 \mathrm{~m} / \mathrm{s}$. The test was stopped when the average evaporator temperature reached about $100^{\circ} \mathrm{C}$. As can be seen, the module is able to handle about $800 \mathrm{~W}$ for this safe maximum evaporator temperature.

The results indicate that at applied power levels below $\sim 200 \mathrm{~W}$, the oscillations inside the device are not vigorous enough. As power levels are increased, increased oscil- 
lating tendencies drastically reduce the thermal resistance, which is defined as

$$
R_{\text {th }}=\left(T_{\text {block }}-T_{\text {air }}\right) / \dot{Q}_{\text {total }}
$$

The entire profile of thermal resistance for the PHP module is shown in Figs. 10(a) and (b). The thermal resistance decreases with increasing applied heat flux. At high heat flux levels, the module successfully operates in both orientations - gravity supported as well as anti-gravity - with comparable thermal resistance. The difference between the two opposing orientations was hardly observable at high heat flux levels. A maximum of about $800 \mathrm{~W}$ could be transferred in both of the orientations (for $T_{e}<\sim 100^{\circ} \mathrm{C}$ ), with overall thermal resistance below $0.1 \mathrm{~K} / \mathrm{W}$.
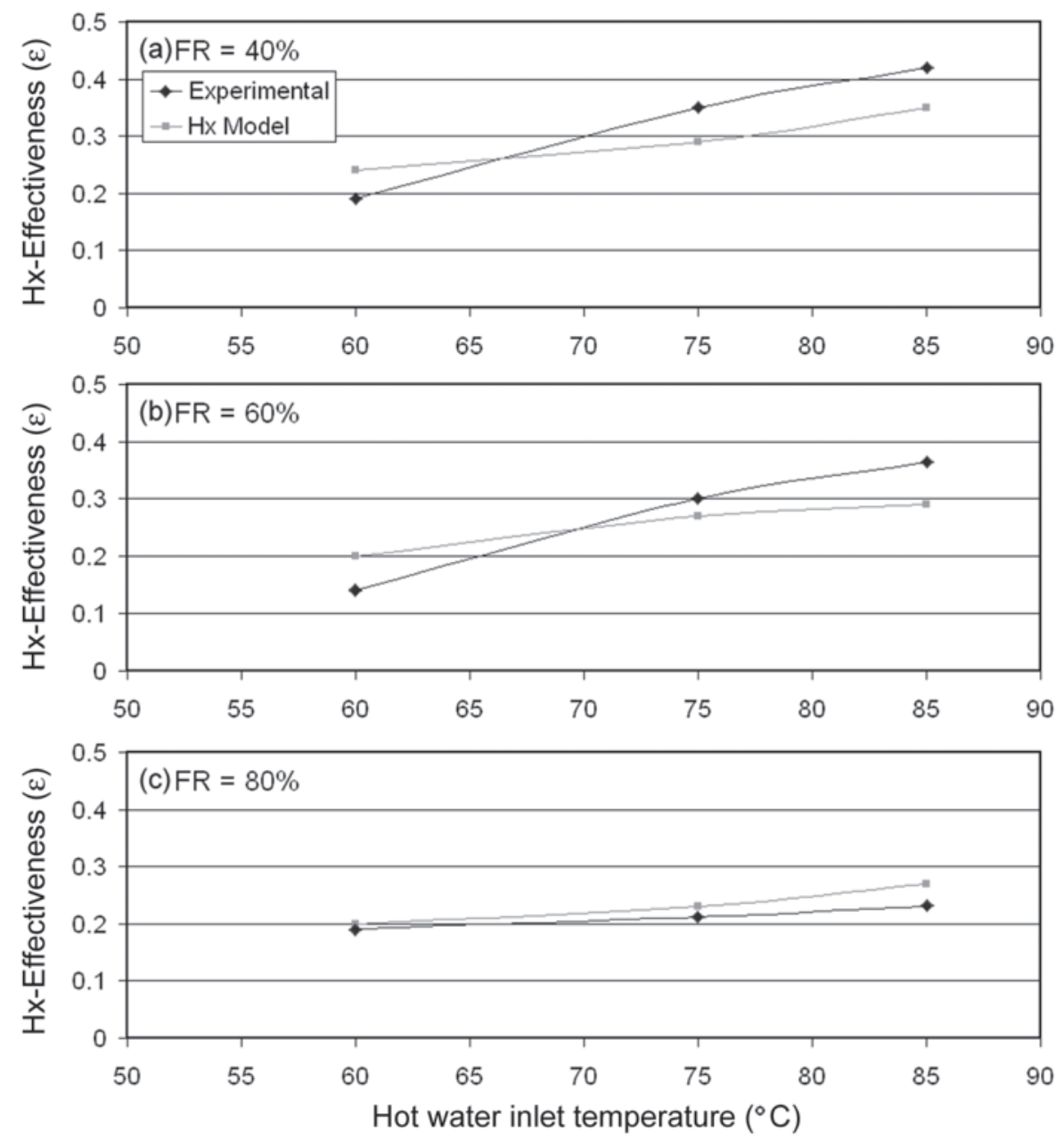

FIG 8: Comparison of experimental data of the temperature-controlled PHP-Hx (Module \#1) with the NTU- $\varepsilon$ heat exchanger model in gravity-assisted orientation: (a) FR $=40 \%$, (b) FR $=$ $60 \%$, and (c) FR $=80 \%$ 


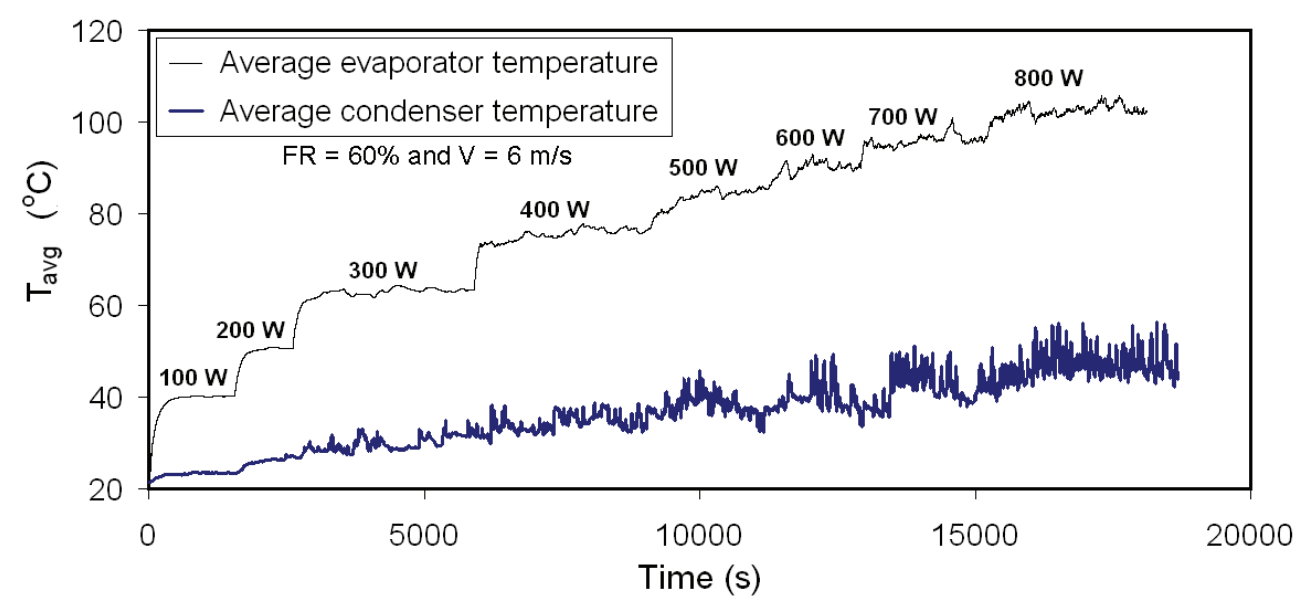

FIG 9: Temporal evolution of the average evaporator and condenser temperatures for the heat flux-controlled PHP heat exchanger (Module \#2) at cooling air $V=6 \mathrm{~m} / \mathrm{s}$

The estimation of the air side heat transfer coefficient $\left(h_{\text {air }}\right)$, as discussed earlier, is shown in Fig. 11. As expected, it increases in the range of $40-100 \mathrm{~W} / \mathrm{m}^{2} \mathrm{~K}$ with increasing centerline air velocity from $1 \mathrm{~m} / \mathrm{s}$ to $6 \mathrm{~m} / \mathrm{s}$. The scatter in the heat transfer coefficient data by repeating these tests was within $\pm 8 \%$. After obtaining $h_{\text {air }}$, the effective thermal conductivity of the PHP module ( $\left.k_{\text {eff }}\right)$ based on the PHP tube cross section can be estimated, as shown in Fig. 12 for both orientations of the device operations. The $k_{\text {eff }}$ increases with applied heat flux and varies between $500 \mathrm{~W} / \mathrm{mK}$ to over $4000 \mathrm{~W} /$ $\mathrm{mK}$; thus, proving the effectiveness of the PHP tubes as high conductivity fin structures. Comparing the data given for effective thermal conductivity of conventional mini-heat pipes in Table 1, it is clear that PHPs may not be as effective as conventional heat pipes, at least in the gravity-assisted operation. Nevertheless, very high thermal conductivities are still achievable that are attractive, especially under situations when the net heat transfer is limited by the external heat transfer coefficient, as in air cooling. This will be further highlighted by the analysis of Module \#3.

\subsection{Heat Flux-Controlled System (Module \#3)}

Figure 13 shows the effect of input heat power on the overall thermal resistance, $R_{\mathrm{th}}$, which is similar to that of Module \#2. It can be clearly seen that at a relatively low heat input power $(50 \mathrm{~W})$, the dissipative losses of fluid friction, acceleration, and gravity are not overcome, resulting in non-significant fluid pulsations inside the device. As the heat power increases $(>100 \mathrm{~W})$, leading to enhanced pumping power, the PHP commences operation; i.e., the pulsations begin. Increasing the heat input power further brings the device to a situation when the heat transfer gets limited by the external (air side) heat transfer coefficient. Dry-out will eventually occur, as reported by Yang et al. (2008).

Figure 14(a) depicts the temperature-time response of the average evaporator temperature for different heat inputs and inclination angles ( $F R=50 \%$ in both of the cases). 

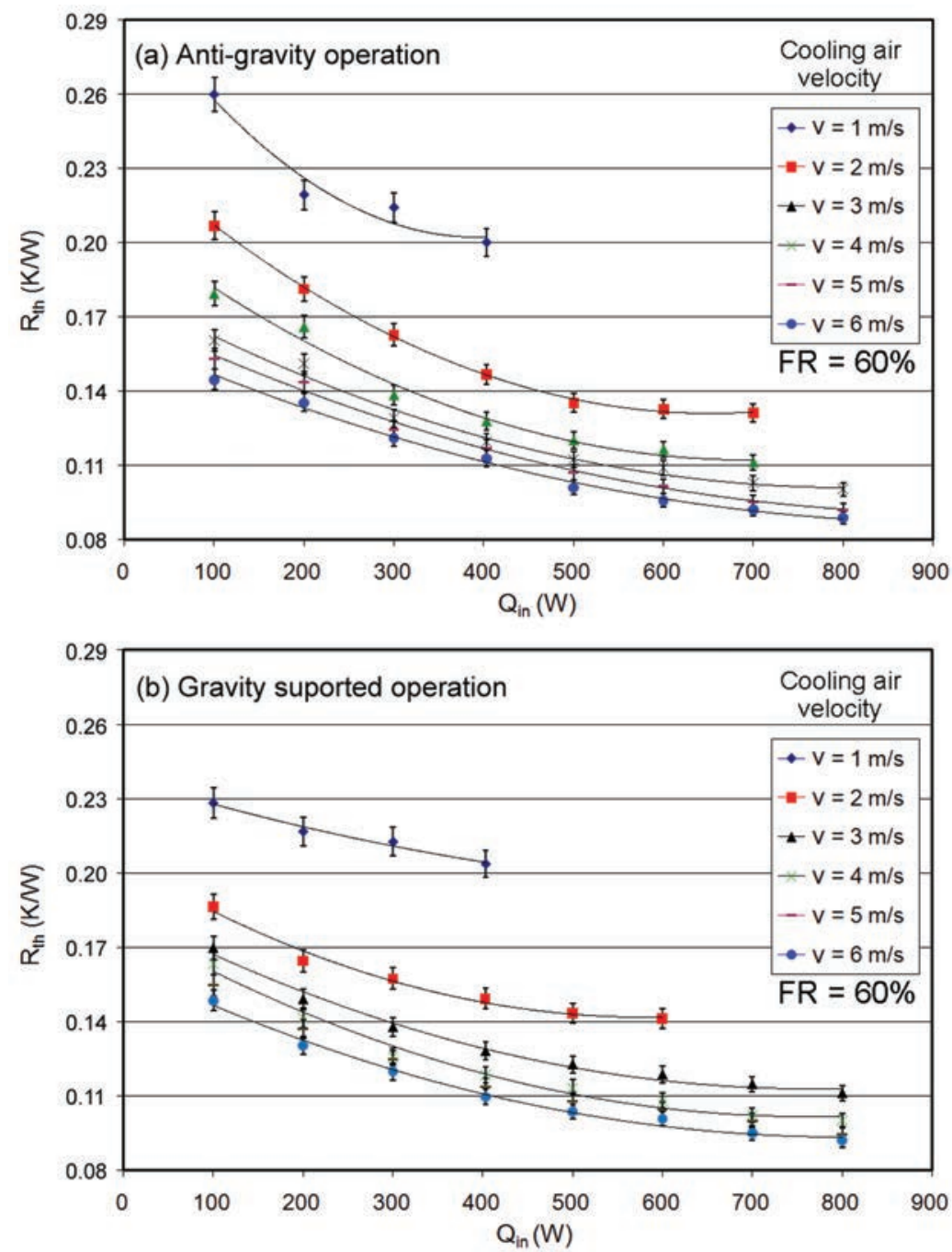

FIG 10: Variation of thermal resistance for the heat flux-controlled PHP heat exchanger (Module \#2) in (a) anti-gravity operation and (b) gravity-supported, heater-down operation

At a given heat input, the inclination angle was continuously changed after quasi-steady state was achieved in one position. At low input power the performance is quite steady for the vertical heater-down position; however, proper operation cannot be guaranteed in the anti-gravity (heater-up) position at low heat fluxes. As can be seen at $100 \mathrm{~W}$, after $\sim 90^{\circ}$ inclination angle, intermittent unsatisfactory operation was observed. Large fluctuations in evaporator temperature commenced once the device was tilted away from horizontal, toward the anti-gravity, heater-up position. As the input heat flux is increased, the thermal performance becomes less and less affected by the inclination 


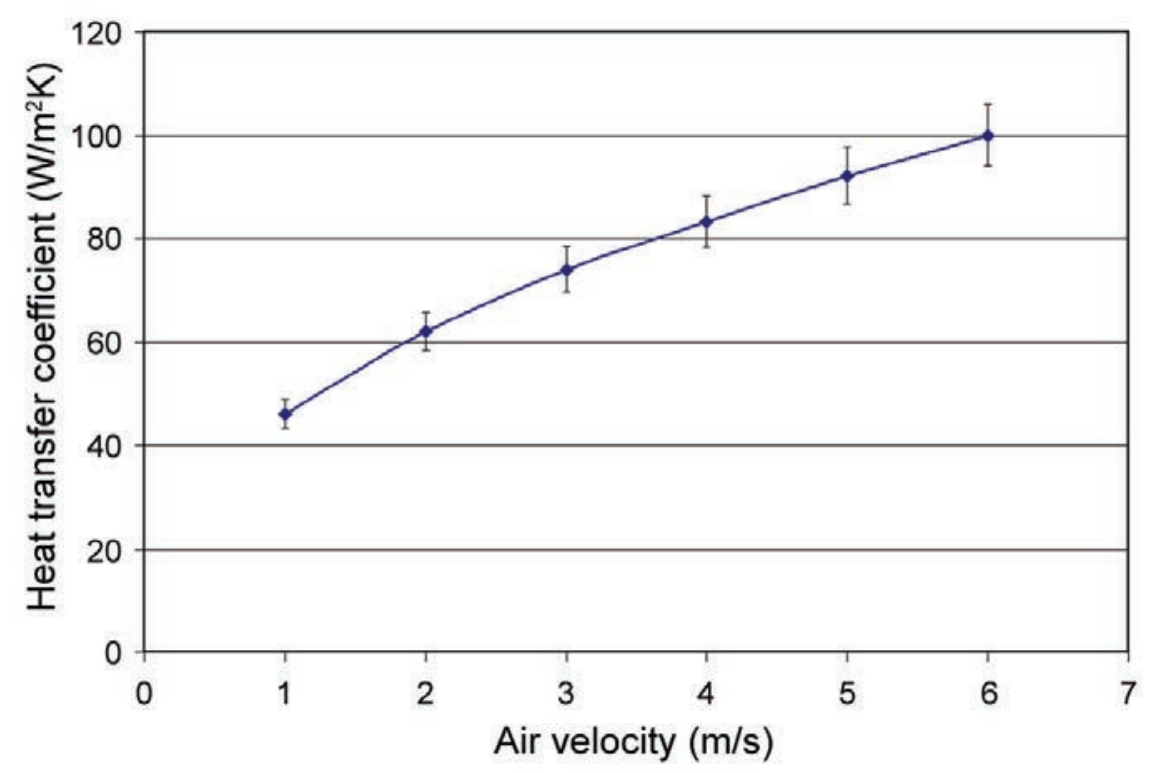

FIG 11: External cooling air side heat transfer coefficient versus center line velocity of cooling air (this is applicable for both Module \#2 and Module \#3)

angle of the device; the evaporator temperature being nearly unchanged for the entire range of inclination angles.

Start-up experiments were also conducted in the vertical, heater-up position. The device was kept in this position undisturbed for an extended period of time (about $48 \mathrm{~h}$ ) and then a power step input was given. The temperature-time response of the average evaporator temperature for different heat inputs ( $F R=50 \%$ in both cases) is shown in Fig. 14(b). It is clear from Fig. 14(b) that a $50 \mathrm{~W}$ power step did not create any pulsations in the device and the thermal resistance was close to the dry device. As the power was increased further than $\sim 100 \mathrm{~W}$, successful anti-gravity start-ups were ensured. Although only one result is shown here, the tests were repeatable many times over with similar operational characteristics.

From Eq. (10), knowing the copper PHP tube geometry and experimentally obtaining $T_{\text {block }}, T_{\text {base }}, T_{\text {air }}$, and $\dot{Q}_{\text {fin }}$, the air side heat transfer coefficient $\left(h_{\text {air }}\right)$ applicable in the experiment described previously was found to be $82 \mathrm{~W} / \mathrm{m}^{2} \mathrm{~K}$. The respective resistances for the dry PHP were: $R_{\text {th-block }}=0.05 \mathrm{~K} / \mathrm{W}, R_{\text {th-fins }}=0.74 \mathrm{~K} / \mathrm{W}$, and $R_{\text {th-total }}=R_{\text {th-block }}+R_{\text {th-fins }}=0.79 \mathrm{~K} / \mathrm{W}$. With this known $h_{\text {air }}$, Eq. (10) can again be used to determine the $\left(k_{f i n}\right)_{P H P}$ for all of the cases of interest when the PHP is partially filled with the working fluid.

For example, from Fig. 13 we notice that the overall thermal resistance of the PHP is approximately in the range of $0.34 \mathrm{~K} / \mathrm{W}$ for the filling ratio between $30 \%$ and $70 \%$ and heat input from $200 \mathrm{~W}$ to $400 \mathrm{~W}$. Therefore, we have, $h_{\text {air }}=82 \mathrm{~W} / \mathrm{m}^{2} \mathrm{~K}$ and $R_{\text {th-block }}=0.05 \mathrm{~K} / \mathrm{W}$, both obtained from the dry PHP test, and because $R_{\text {th-total }}=0.34$ $\mathrm{K} / \mathrm{W}$, we get $R_{\text {th-fins }}=R_{\text {th-total }}+R_{\text {th-block }}=0.29 \mathrm{~K} / \mathrm{W}$. For each case, $T_{\text {block }}$ and $T_{\text {base }}$ 

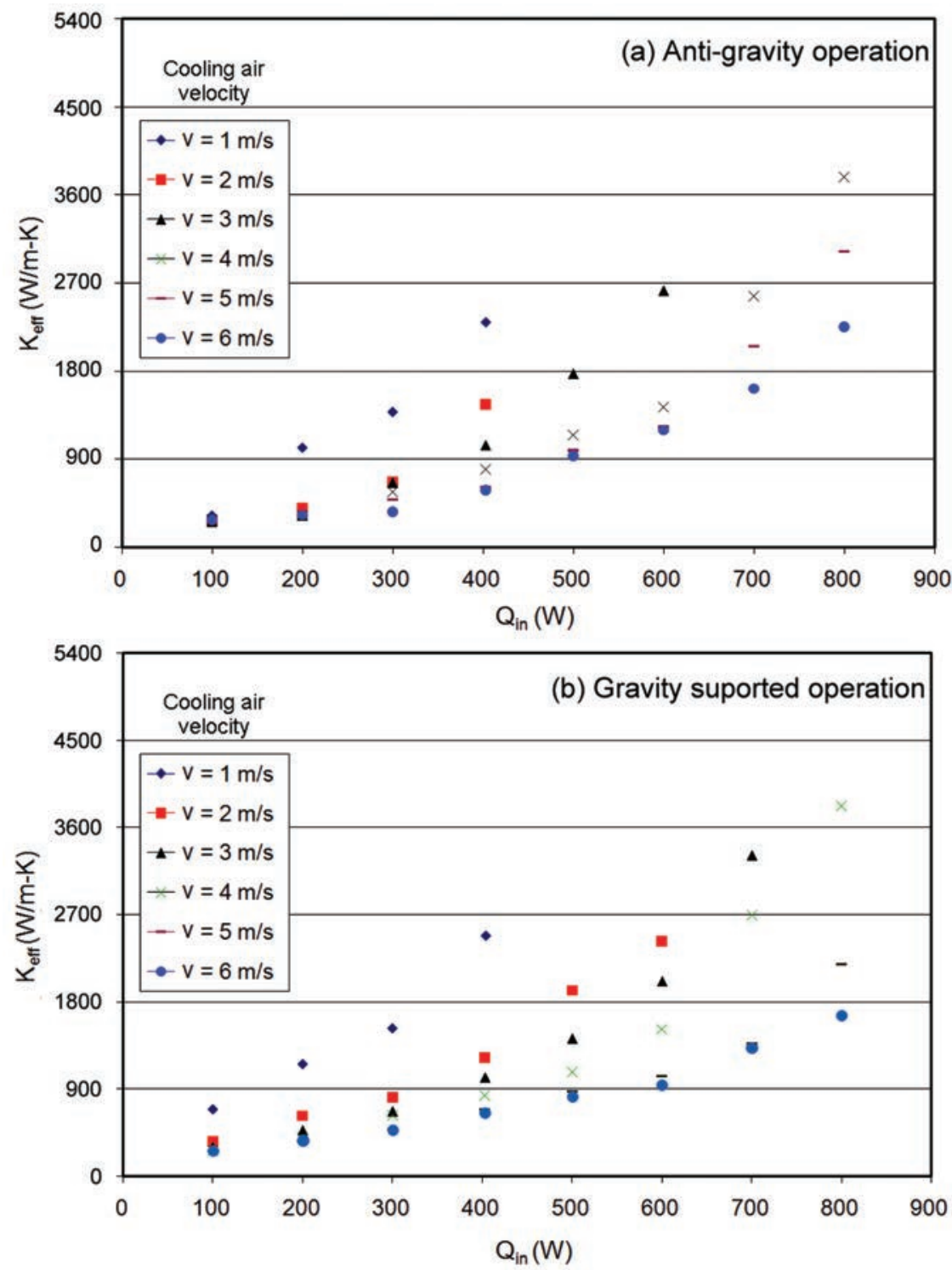

FIG 12: Effective thermal conductivity for the heat flux-controlled PHP heat exchanger (Module \#2) at FR $=60$, as estimated from the extended surface fin analogy in (a) anti-gravity operation and (b) gravity-supported, heater-down operation

were experimentally determined and the value of $R_{\text {th-block }}$ was rechecked and confirmed to be about $0.05 \mathrm{~K} / \mathrm{W}$. Thus, from Eq. (10), the average effective thermal conductivity (based on the entire cross section area; i.e., tube $\mathrm{OD}=3.0 \mathrm{~mm}$ ) in the range $\mathrm{FR}=30 \%$ to $70 \%$ and input power $200-400 \mathrm{~W}$ was found to be approximately, $\left(k_{f i n}\right)_{P H P}=4500 \mathrm{~W} / \mathrm{mK}$. The essence of this analysis is shown in Table 2 and highlighted in Fig. 15. 


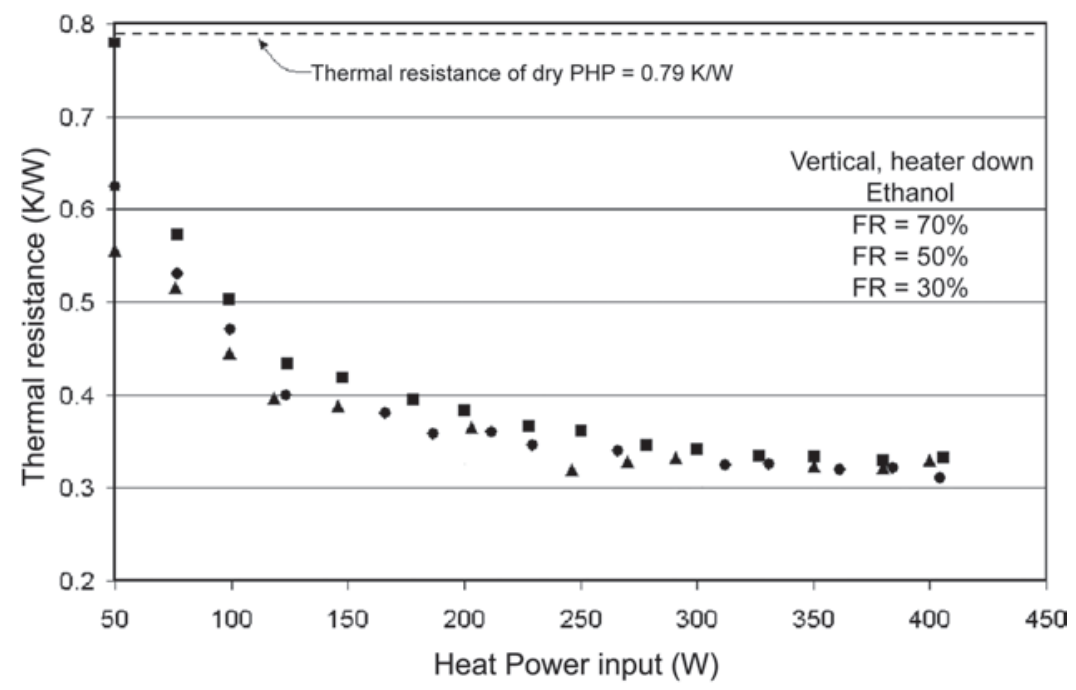

FIG 13: Variation of thermal resistance for the heat flux-controlled PHP heat exchanger (Module \#3) in gravity-supported, heater-down operation (coolant air velocity is fixed at $V=3.5 \mathrm{~m} / \mathrm{s}$ )

It is clear that the nature of the mixed conduction-convection heat transfer represented by Eq. (10) (and highlighted by Fig. 16 and Table 2) is such that the heat throughput becomes limited by the external heat transfer coefficient after a certain value of the fin thermal conductivity is achieved. This is highlighted in Fig. 15, which plots the net heat throughput achievable by a fin system [using Eq. (11)] as a function of the thermal conductivity of the fin, by taking the temperature data from Table 2 as applicable to Module 3. With the achieved effective thermal conductivity, both the tested PHP modules under heat flux-controlled conditions nearly acted as a super-fin system. While in vertical heater-down position, the mini-heat pipes may give a slight advantage over the PHPs; the fact that PHPs can operate with near equal performance level in all orientations makes a very strong case in their favor. In addition, as compared to solid copper fins, there is a sizable weight advantage.

The fin analogy, as presented above, indeed has some obvious limitations. From Eq. (10), it is quite easy to know the effect of the length of solid fin or the air side external heat transfer coefficient on the net heat throughput for fin materials with constant thermal conductivity. These trends may not be extrapolated for the case of PHPs or for mini-heat pipes. In the case of PHPs, for a given heat throughput an increase in overall device length will amount to greater dissipative frictional losses affecting its effective thermal conductivity, while for conventional mini-heat pipes, the maximum performance until dry-out will decrease with an increase in length. Similarly, an increase in the external heat transfer coefficient may not always guarantee an increased performance of mini-heat pipes. Referring to Fig. 16, if a conventional heat pipe is operating at a temperature $T_{1}$ with heat input of $\dot{Q}_{1}$ very close to the capillary dry-out power $Q_{\text {dry-1 }}$, under such operating conditions if the condenser capacity is increased by either lowering the coolant temperature or increasing its flow rate, there is a risk of a dry-out to occur. This will happen since the operating temperature drops to $T_{2}$, for which $\dot{Q}_{1}$ is too high. Although there is no well-defined adiabatic oper- 


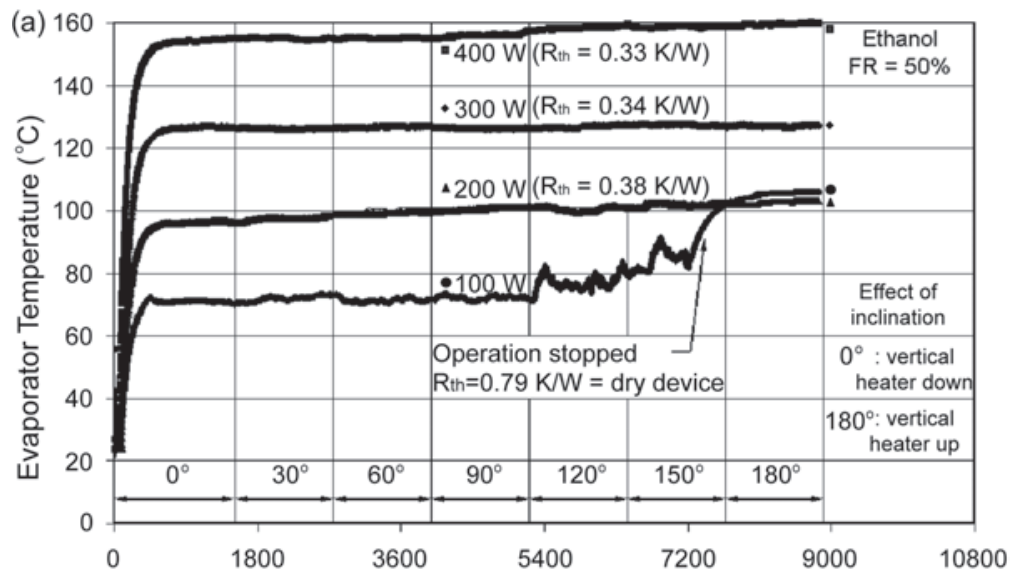

(b)

Time (s)

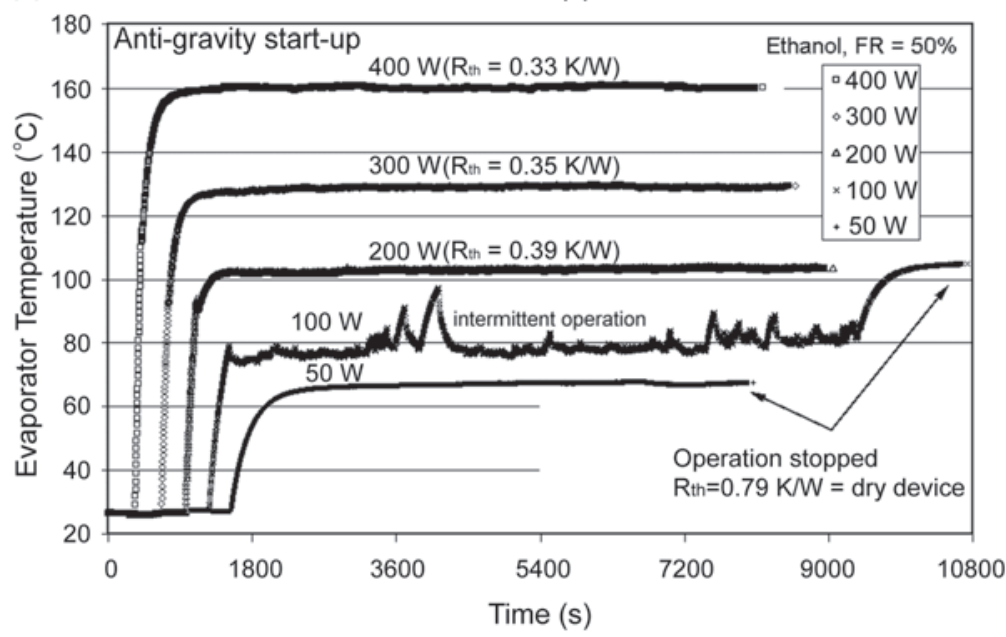

FIG 14: (a) Effect of operating orientation on average evaporator temperature of the CLPHP. Above $100 \mathrm{~W}$, the performance is nearly independent of the orientation and (b) anti-gravity (heater on top) start-up by step power input to the CLPHP

ating temperature for PHPs, a similar trend regarding the effect of condenser capacity may occur since increasing the condenser capacity affects not only the thermophysical properties of the working fluid, but as a side effect, alters the slug-annular flow pattern transitions, thereby altering the final performance (Khandekar, 2004; Yang et al., 2009). This aspect has to be addressed during practical designing and needs further understanding.

\section{SUMMARY AND CONCLUSIONS}

We presented two types of PHP-based heat exchangers: (1) a temperature-controlled liquid-liquid heat exchanger and (2) a heat flux-controlled air-cooled module. Typical 
applications of such PHP heat exchangers may range from process waste heat recovery to high heat flux handling for power electronics applications. The following conclusions can be drawn from the present study:

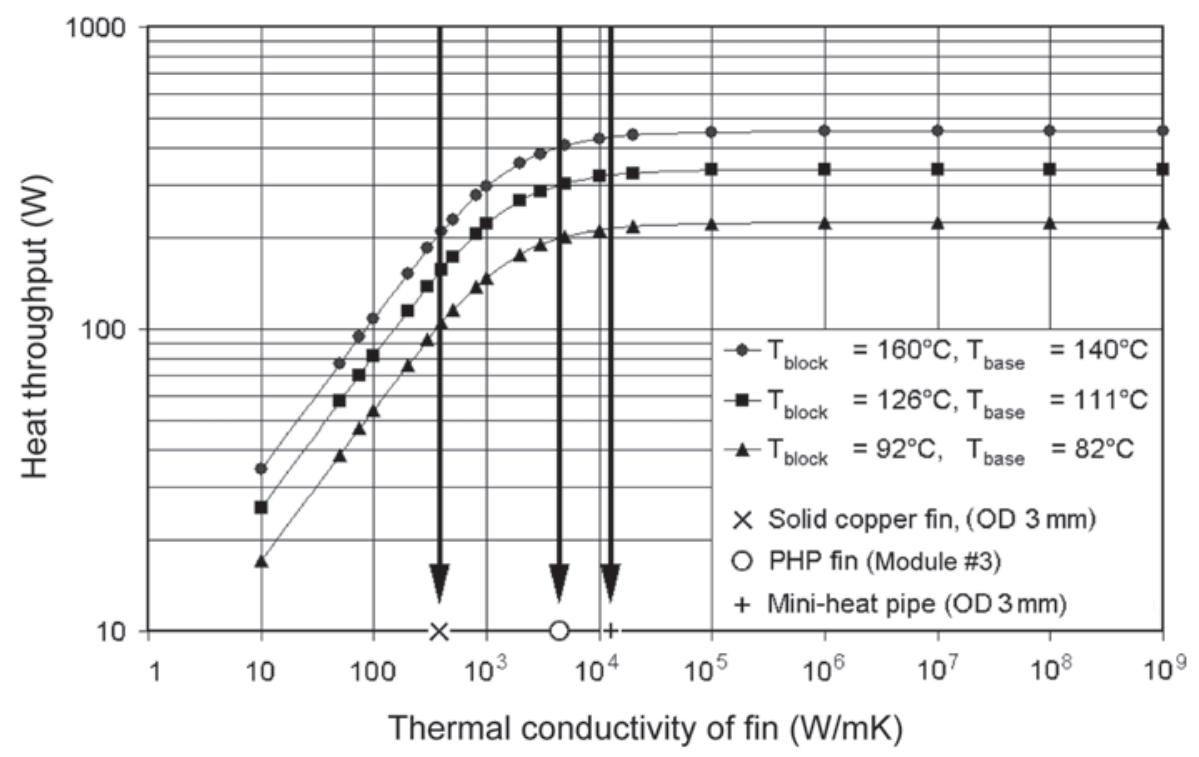

FIG 15: Heat throughput from the present experiment (vertical heater-down position) as compared to an extended surface fin system with increasing thermal conductivity [Eq. (10)]

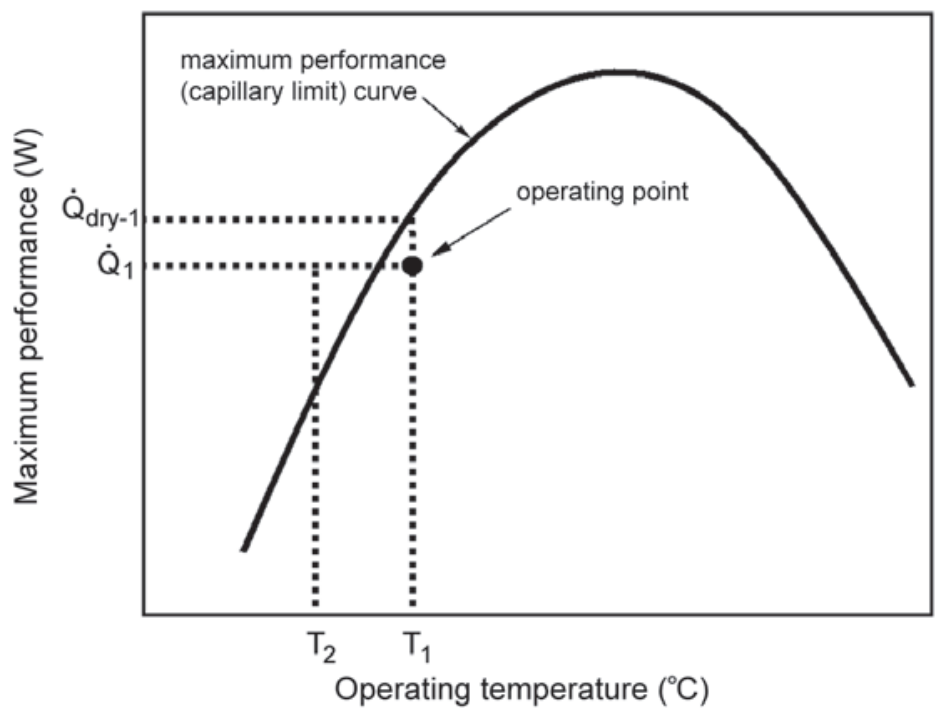

FIG 16: Dry-out in a conventional wicked heat pipe due to increase in condenser capacity 
TABLE 2: Extended surface fin analogy (vertical heater-down position) for Module \#3

\begin{tabular}{|c|c|c|c|c|c|c|}
\hline \multirow[b]{2}{*}{$\begin{array}{l}T_{\text {block }} \\
\left({ }^{\circ} \mathrm{C}\right)\end{array}$} & \multirow[b]{2}{*}{$\begin{array}{l}T_{\text {base }} \\
\left({ }^{\circ} \mathrm{C}\right)\end{array}$} & \multirow[b]{2}{*}{$\begin{array}{l}T_{\text {air }} \\
\left({ }^{\circ} \mathrm{C}\right)\end{array}$} & \multicolumn{4}{|c|}{ Heat throughput } \\
\hline & & & $\begin{array}{c}\text { Solid copper } \\
\text { fin } \\
(380 \mathrm{~W} / \mathrm{m} \mathrm{K})\end{array}$ & $\begin{array}{c}\text { PHP fin } \\
(4500 \\
W / m ~ K)\end{array}$ & $\begin{array}{c}\text { Mini-heat } \\
\text { pipe } \\
(12344 \\
\text { W/m K) }\end{array}$ & $\begin{array}{l}\text { Superconductor } \\
(\infty \mathbf{W} / \mathbf{m ~ K})\end{array}$ \\
\hline 160 & 140 & 24 & $206 \mathrm{~W}$ & $400 \mathrm{~W}$ & $431 \mathrm{~W}$ & $451 \mathrm{~W}$ \\
\hline 126 & 111 & 24 & $154 \mathrm{~W}$ & $300 \mathrm{~W}$ & $323 \mathrm{~W}$ & $338 \mathrm{~W}$ \\
\hline \multirow[t]{3}{*}{92} & 82 & 24 & $103 \mathrm{~W}$ & $200 \mathrm{~W}$ & $215 \mathrm{~W}$ & $225 \mathrm{~W}$ \\
\hline & & & \multicolumn{4}{|c|}{ Weight } \\
\hline & & & $62.9 \mathrm{gm} / \mathrm{m}$ & $\begin{array}{c}36.1 \mathrm{gm} / \mathrm{m} \\
\text { (with } 50 \% \\
\text { ethanol) }\end{array}$ & $33.7 \mathrm{gm} / \mathrm{m}$ & - \\
\hline
\end{tabular}

Note: $N=40$ fins (i.e., 40 turn PHP); $L=125.0 \mathrm{~mm} ; h_{\text {air }}=82 \mathrm{~W} / \mathrm{m}^{2} \mathrm{~K} ; \mathrm{OD}=3.0 \mathrm{~mm}$ for the copper fins and super-conductor; $\mathrm{OD} / \mathrm{ID}=3.0 / 2.0 \mathrm{~mm}$ for the $\mathrm{PHP}$ and $\mathrm{OD} / \mathrm{ID}=3.0 / 2.5 \mathrm{~mm}$ for the mini-heat pipe.

1. The effectiveness values for the temperature-controlled PHP-based heat exchanger system, operating under gravity-assisted mode, were of the order of $\sim 0.25-0.45$; the heat exchanging PHP tubes being completely bare and un-finned. In the antigravity mode a higher temperature difference was needed to operate the system. In this module, $\mathrm{FR}=40 \%$ gave better results as compared to $\mathrm{FR}=60 \%$ and $80 \%$.

2. The NTU- $\varepsilon$ methodology of analysis for a conventional heat pipe heat exchanger also is applicable for the PHP heat exchanger. This is because of the fact that the heat capacity ratio $C_{\min } / C_{\max }$ is still reasonably small for a PHP (although it may not be equal to zero). More systematic studies and data are required for further establishing this methodology of analysis for different PHP configurations and boundary conditions thereof.

3. The tests indicated that the heat flux-controlled configurations are probably better suited for PHP-based applications. These devices can handle large heat fluxes. Effective thermal conductivities ( $k_{\text {eff }}$ ) of the air-cooled PHP module have been investigated by using extended surfaces fin analogy; $k_{\text {eff }}$ values for the tested PHP are found to be of the order of 4-12 times that of pure copper. Effective thermal conductivity decreases with increasing heat flux. Dry-out fluxes could not be recorded due to experimental setup limitations.

4. Overall thermal resistances have been found to be very low (of the order of $\sim 0.2$ KW or lower), even though air cooling was employed. For a certain value of cooling air velocity, as the applied heat throughput increases the value of overall thermal resistance decreases. The slopes of curves for thermal resistance plotted 
against the applied heat flux were initially found to be high, decreasing as the value of applied flux increases. For a given heat flux, as the cooling air velocity increases, the thermal resistance initially decreases faster and later levels off beyond $\sim 3 \mathrm{~m} / \mathrm{s}$.

5. For the low values of heat throughput, this air-cooled PHP module performs better (in terms of thermal resistance and effective thermal conductivity) in gravitysupported orientation than in anti-gravity orientation. As the applied heat flux increases, gravity does not play a significant role; comparable thermal resistances are obtained in both orientations. As compared to mini-cylindrical heat pipes, even if the effective thermal conductivity of PHPs is somewhat smaller, there is considerable advantage in the use of PHPs, especially in cases where the external heat transfer coefficient limits the overall heat transfer and anti-gravity operation may occur. In addition, the fact that a PHP module operates equally well in all orientations is another major advantage.

\section{ACKNOWLEDGMENTS}

The work is supported by financial grants from Bhabha Atomic Research Center, Department of Atomic Energy, Government of India.

\section{REFERENCES}

Akachi H., Structure of a Heat Pipe, US Patent Number 4921041, 1990.

Akachi, H., Polášek, F., and Štulc, P., Pulsating heat pipes, Proc. of 5th International Heat Pipe Symposium, Melbourne, Australia, pp. 208-217, 1996.

Das, S.P., Nikolayev, V.S., Lefevre, F., Pottier, B., Khandekar, S., and Bonjour J., Thermally induced two-phase oscillating flow inside a capillary tube, Int. J. Heat Mass Transfer, vol. 53, pp. 3905-3913, 2010.

Incropera, F.P., Dewitt, D., Bergman, T. L., and Lavine, A. S., Fundamentals of Heat and Mass Transfer, 6th ed., New York: Wiley, 2007.

Kays, W.M. and London, A. L., Compact Heat Exchangers, New York: McGraw-Hill, 1984.

Khandekar, S., Thermo-hydrodynamics of closed loop pulsating heat pipes, Ph.D. dissertation, Universitaet Stuttgart, Germany (accessed June 2011; http://elib.uni-stuttgart.de/opus/volltexte/2004/1939/), 2004.

Khandekar, S., Pulsating heat pipe heat exchangers, Proc. of 21 st International Symposium on Transport Phenomena, Kaohsiung City, Taiwan, ROC, November, 2010.

Khandekar, S., Panigrahi, P.K., Lefèvre, F., and Bonjour, J., Local hydrodynamics of flow in a pulsating heat pipe: A review, Front. Heat Pipes, vol. 1, p. 023003, 2010.

Tang, X., Hammel, E., Findl, W., Schmitt, T., Thumfart, D., Groll, M., Schneider, M., and Khandekar, S., Study of AlSiC metal matrix composite based flat plate thin heat pipe, Proc. of 13th International Heat Pipe Conference, Shanghai, China, 2004.

Vasiliev, L.L., Heat pipes in modern heat exchangers, Appl. Therm. Eng., vol. 25, pp. 1-19, 2005.

Yang, H., Khandekar, S., and Groll, M., Operational limit of closed loop pulsating heat pipes, Appl. Therm. Eng., vol. 28, no. 1, pp. 49-59, 2008.

Yang, H., Khandekar, S., and Groll, M., Performance characteristics of pulsating heat pipes as integral thermal spreaders, Int. J. Therm. Sci., vol. 48, no. 4, pp. 815-824, 2009.

Zhang, H. and Faghri, A., Advances and unsolved issues in pulsating heat pipes, Heat Transfer Eng., vol. 29, no. 1, pp. $20-44,2008$. 